\title{
Herbstliche Farbenpracht des Amberbaums (Liquidambar styraciflua)
}

Hilke Steinecke

Die Gattung Liquidambar umfasst etwa sechs Arten. Die Blätter ähneln denen eines Ahorns, sie sind fünflappig, stehen aber wechselständig. Die gelblich grünen kugeligen Blütenstände erscheinen im Frühjahr, die darauf folgenden Fruchtstände sind ebenfalls kugelig. Sie erinnern an kleine zusammengerollte Igel. Den deutschen Namen Amberbaum erhielt die aus dem östlichen Nordamerika stammende Art Liquidambar styraciflua wegen ihrer z. T. bernsteinfarbigen Herbstfärbung (Amber $=$ Bernstein). In Nordamerika tragen Amberbäume neben Ahorn-Arten und Eichen maßgeblich zum Indian Summer bei. Nach einer alten Legende zeigt sich in den roten Blättern das Blut der im Herbst erlegten Bären, das in den Boden sickert und dann angeblich von den Amberbäumen aufgenommen wird. Ist der Baum unbelaubt, fallen die mit Korkleisten besetzten Äste auf. Der Saft von Liquidambar hat

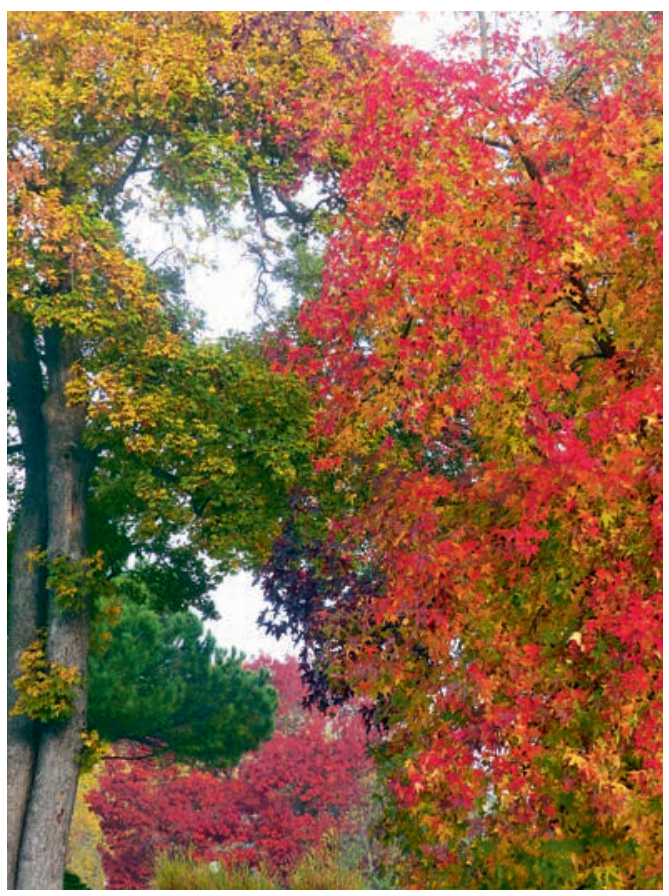

Abb. 1: Herbstlicher Amberbaum im Palmengarten. (Foto: H. Steinecke) einen streng-aromatischen Duft und wird zur Kaugummiherstellung verwendet. Das Holz wird zu Möbeln und als Furnier verarbeitetet, man bezeichnet es auch als Nuss-Satinholz. Blätter, Wurzeln und Rinde können zudem zum Färben von Stoffen verwendet werden. Der Amberbaum mag sonnige, freie Standorte. Im Palmengarten stehen vier Exemplare zwischen dem Eingang Siesmayerstraße und Rosengarten. Sie gehören zu unseren Bäumen mit regelmäßig schönster Herbstfärbung. Bei viel Sonnenschein wie im Herbst 2018 fällt die Färbung des Laubes besonders intensiv aus. Die Vielfalt der Blattfarben, die gleichzeitig an einem Baum zu erkennen sind, begeistert jedes Jahr immer wieder.

\section{Anschrift der Autorin}

Dr. Hilke Steinecke, Palmengarten Frankfurt, Siesmayerstraße 61, 60323 Frankfurt, E-Mail: hilke.steinecke@ stadt-frankfurt.de

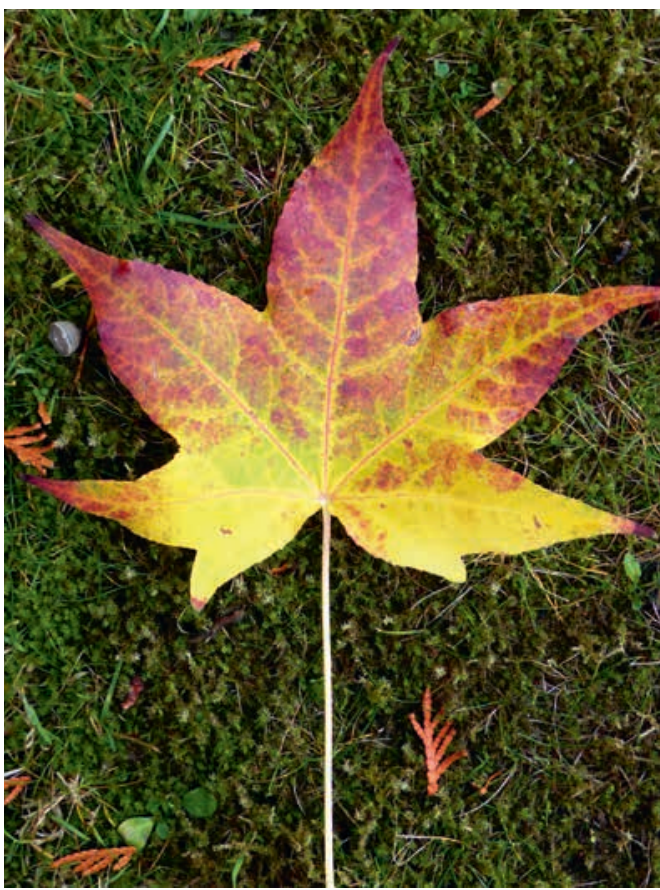

Abb. 2: Rot, Gelb und Grün in einem einzigen Blatt des Amberbaums. (Foto: H. Steinecke) 


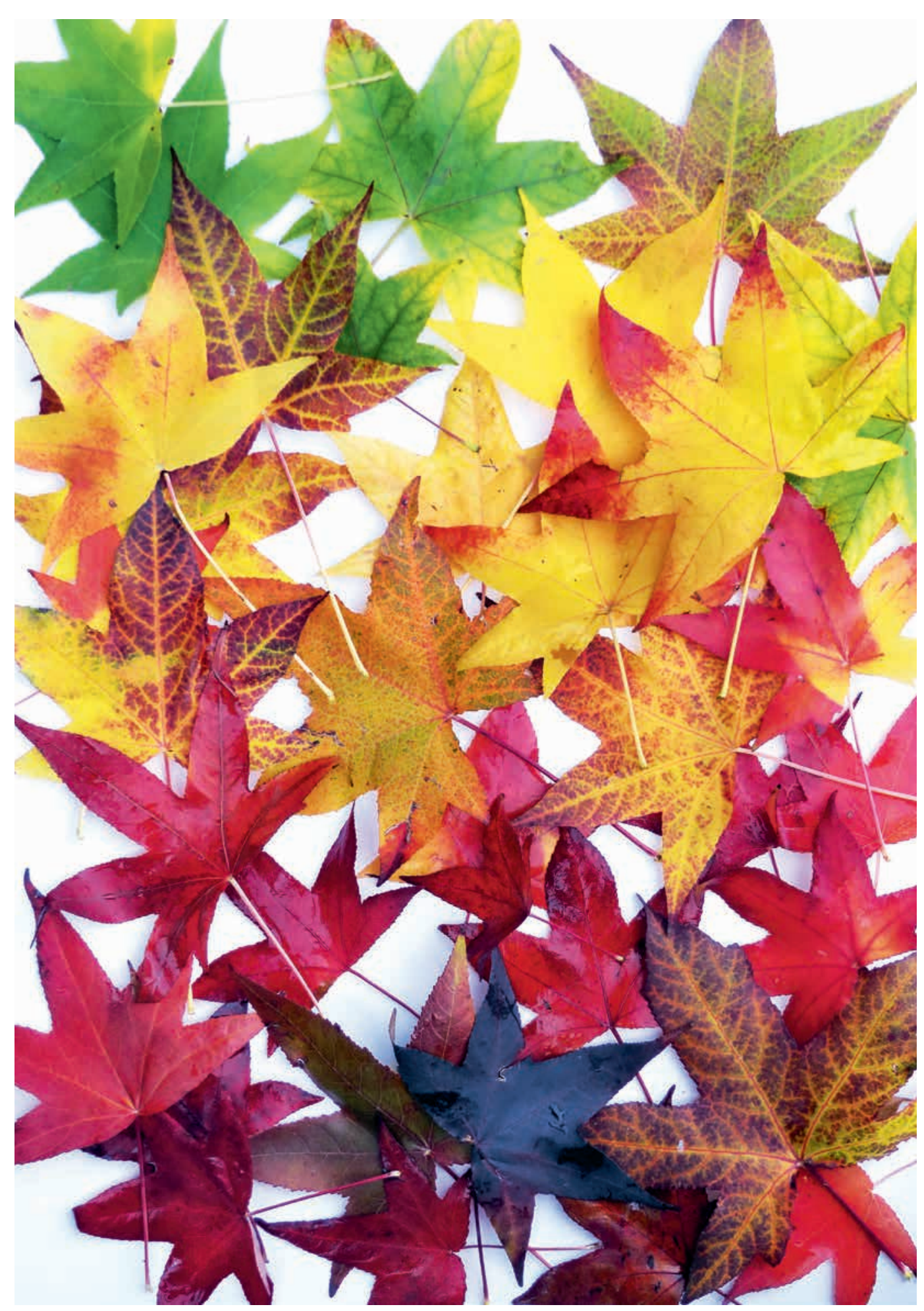

Abb. 3: Farbspektrum der Blätter des Amberbaums. (Foto: H. Steinecke) 